\title{
DEL SALÓN AL MONASTERIO. \\ LEOCADIA ZAMORA, UN RETRATO DE MUJER EN LA CORTE ISABELINA
}

FROM THE HALL TO THE MONASTERY. LEOCADIA ZAMORA,

A PORTRAIT OF A WOMAN IN ISABEL'S COURT

\author{
Mariángeles Pérez-Martín ${ }^{1}$ \\ Universitat de València \\ Mas si algún eco del arpa, \\ Que hoy a romper me decido, \\ Logra vencer al olvido \\ $Y$ al voraz tiempo burlar, \\ A par de mi nombre tu nombre querido \\ Por siglos futuros se oirá resonar. \\ Gertudis Gómez de Avellaneda (1850: 311 )
}

\section{RESUMEN}

Leocadia Zamora Quesada (Puerto Príncipe, 1819 - Oviedo, 1891) fue la mujer más bella de la España de Isabel II. Así lo aseguraba un artículo de Blanco y Negro en 1959. El periodista hacía tal afirmación a la vista del retrato de Federico de Madrazo y Kuntz, 1847, una obra que causó sensación en la época. La retratada mantuvo buena relación con el pintor, como se aprecia en la correspondencia. Leocadia alcanzó gran relieve social en la corte tras instalarse en Madrid junto a su familia, poseía una voz musical con la que amenizaba las veladas en salones como los de la condesa del Montijo, y fue muy amiga de Francisca y Eugenia de Montijo, y de la reina Isabel II. Tras recorrer varias ciudades europeas y, según algunas crónicas, tras varios amores frustrados, entre ellos su sobrino Rafael Zamora y Pérez de Urría, III marqués de Valero de Urría, se recluyó en un monasterio.

Palabras clave: Isabel II, sociabilidad femenina, monjas fundadoras, Federico de Madrazo y Kuntz, retrato siglo XIX, Washington Irving, conde de Peñalver.

\section{ABSTRACT}

Leocadia Zamora Quesada (Puerto Príncipe, 1819 - Oviedo, 1891) was the most beautiful woman in the Spanish court of Isabel II. At least that says an article published in Blanco y Negro (1959). The journalist made this statement watching the portrait by Federico de Madrazo y Kuntz (1847). This work caused a great sensation at the time. The portrayed maintained good relationship with the artist, like can

1 M.Angeles.Perez-Martin@uv.es. Esta investigación se ha desarrollado con una Ayuda del Ministerio de Educación, Cultura y Deporte en el Programa de Formación de Profesorado Universitario (FPU14/04087). 
see in their letters. Leocadia achieved great social relief in Court after settling in Madrid with his family. She had a musical voice that enlivened the evenings in salones like the Countess Montijo, and was a close friend of Francisca and Eugenia Montijo, and Queen Isabel II. After a tour of several European cities and, according to some accounts, after some failed loves, including her nephew Rafael Zamora Perez de Urría, III Marquis Valero de Urría, retreated to a monastery.

Keywords: Isabel II, Female sociability, Founding nuns, Federico de Madrazo y Kuntz, Nineteenth Century portrait, Washington Irving, Count of Peñalver.

En 1924 veía la luz el libro Retratos de mujeres españolas del siglo XIX, un texto que había sido premiado en el concurso convocado por la Junta de Iconografía Nacional en 1920, y cuyo objeto - tal como sus autores Joaquín Ezquerra del Bayo y Luis Pérez Bueno afirman en el prólogo- era «documentar con fechas las biografías de ciertas damas, fechas que ni aun ellas mismas recordarían». La intención del texto era mostrar únicamente su influencia en el periodo que marcaba el concurso, pues: "a casi nadie puede interesar cuando se trata, por ejemplo, de una actriz si actuó hasta un determinado año. Basta saber fue notable cierto periodo, aunque luego desaparezca sin dejar huella» (1924: VII). Esta opinión fue la tónica general en lo que a historiografía sobre mujeres se refiere durante el siglo xIX y buena parte del xx. Afortunadamente, hoy somos conscientes de la trascendencia de «dejar huella» $y$ de cómo la disciplina histórica ha silenciado las experiencias y contribuciones de las mujeres. Por eso - como señala Mónica Bolufer en su estudio-, «la historia de las mujeres asumió, desde sus inicios, la necesidad y el reto de dar a conocer las vidas y experiencias femeninas, utilizando para ello, entre otros recursos, el enfoque biográfico» (2014: 87).

En el mencionado texto premiado, Ezquerra y Bueno (1924) reunían más de ciento ochenta retratos de mujeres entre los que había reinas, aristócratas y mecenas, incluso algunas de ellas, además de destacar por su posición y belleza, habían dejado su impronta como cantantes, pintoras o escritoras. Una de las damas seleccionadas por los autores en su recopilación era Leocadia Zamora y Quesada (Puerto Príncipe, 1819 - Oviedo, 1891), cuya reseña acompañaban del magnífico retrato que Federico de Madrazo y Kuntz (Roma, 1815 - Madrid, 1894) había realizado en 1847 por encargo de la madre de la modelo². Con estas palabras reseñaban los autores la biografía de Leocadia, incluida en la categoría de «belleza»:

Brilló esta dama, por su extraordinaria belleza y dotes de talento y gracia singular, en la Corte de D. ${ }^{a}$ Isabel II y en los salones de la Condesa del Montijo, "centro de la alta política», según

196

2 Leocadia Zamora, 1847. Madrid, Colección Particular. Probablemente, debido al gran éxito de la pintura el hermano del pintor, Luis de Madrazo Kuntz (Madrid, 1825 - 1897), poco después copió el retrato (c. 1847-48).

Dossiers Feministes, 21, 2016, 195-214 - ISSN: $1139-1219$ - DOI: http://dx.doi.org/10.6035/Dossiers.2016.21.12 
frase del erudito académico Pérez de Guzmán. Era la época de los grandes bailes, y bailando se caminaba hacia la revolución. Y así en los bailes de la Condesa de Vilches, de Superunda, de los señores de Lasala, de Osma y tantos otros nobles o plebeyos enriquecidos, en todos los salones figuró la señorita de Zamora, distinguiéndose por su belleza, espléndida de encantos, siendo adorada por cuantos tuvieron la dicha de tratarla.

Era hija D. ${ }^{a}$ Leocadia, de D. Manuel Zamora y de D. ${ }^{a}$ Dolores de Quesada, noble matrimonio cubano que estableció su residencia en esta Corte, entrando pronto en relaciones con toda la sociedad aristocrática. El triunfo de Leocadia Zamora aún se acrecentó entre la gente cortesana por la amistad íntima que contrajo con D. ${ }^{a}$ Isabel II y con la que años más tarde había de ser Emperatriz de los franceses. Durante los años de la Revolución, figuró ya muy poco $D$. $^{a}$ Leocadia en las mundanas fiestas. Luego, misterios del corazón humano, contrariedades del espíritu, reprimidas vocaciones, lo cierto es que se retiró al convento de Carmelitas de Alba de Tormes. Y poco tiempo después de la Restauración, hizo una breve aparición en Madrid para trasladarse a Oviedo, donde fundó a sus expensas un convento de la Orden de Carmelitas, y donde piadosamente terminó sus días. La única hermana que tuvo $D{ }^{a}{ }^{a}$ Leocadia casó con el Conde de Peñalver, y fue madre del ex Alcalde de Madrid, de grata memoria.

Esta dama de origen cubano fue una mujer que, sin haber destacado profesionalmente en ninguna disciplina, gozó de la admiración de importantes personalidades de la época. Se distinguió por su belleza y alcanzó gran relieve social en la corte isabelina tras instalarse en Madrid junto a su familia. El estudio de su figura, inscrita en el contexto madrileño de mitad del siglo $\mathrm{xx}$, permite reflexionar sobre las circunstancias históricas y los valores simbólicos que la biografiada compartía con sus contemporáneos, y cómo esas normas y convenciones, que en muchas ocasiones se presentan como marcos fijos, adquieren múltiples matices en función del sujeto - además de la pertinencia historiográfica en aras de recuperar esas vidas «robadas» del pasado, olvidadas por la historia oficial (Bolufer, 2014: 94).

\section{1.- De los bailes y salones madrileños}

Leocadia Zamora nació en Puerto Príncipe, en 1819, era hija de José María Zamora Coronado y de María Ángeles de Quesada y Guerra³ ${ }^{2}$ dama descendiente de una familia de antiguo linaje en la ciudad cubana. José María estudió leyes en Guatemala, se graduó en la

\footnotetext{
3 Sobre el nombre de los padres de Leocadia Zamora existen divergencias en las reseñas de los diversos autores. En el texto de Ezquerra y Bueno (1924) se dice que era hija de Manuel Zamora y Dolores de Quesada, mientras que en el artículo de Monte-Cristo (1907) se afirma que su padre era Nicolás Zamora. El mismo autor años más tarde (1921) señala que Manuel Zamora y Dolores Quesada eran sus padres. Sin embargo, Fernández Piza (1979) en su artículo sobre "Don José María de Zamora y Coronado» afirma que este se casó con María Ángeles Quesada y Guerra, y que Leocadia Zamora era hija de ambos. Por otro lado, en el Archivo Histórico Nacional (en adelante AHN) existen varios documentos relativos a la familia Zamora sobre la renuncia y cesión de los derechos a la herencia de $M .^{a}$ de los Ángeles Quesada, otorgados por su hija M. ${ }^{a}$ Dolores Zamora a favor de sus hermanos, y otros por Leocadia Zamora y Quesada a favor de los hijos de su hermana Joaquina.
} 
Universidad de San Carlos trasladándose después a España para ampliar conocimientos. El matrimonio Zamora-Quesada tuvo una numerosa descendencia: Rafael Zamora y Quesada se casó con la marquesa de Valero de Urría, descendiente de los primeros conquistadores de la isla; de este matrimonio nacería Rafael Zamora y Pérez de Urría ${ }^{4}$, III marqués de Valero de Urría, del cual según afirmaron algunas crónicas estuvo enamorada su tía Leocadia. Además, su hermana Dolores Zamora Quesada se casó con José Narciso de Peñalver y Peñalver, y fueron padres del que sería alcalde de Madrid, Nicolás Peñalver Zamora, III conde de Peñalver y $\vee$ marqués de $\operatorname{Arcos}^{5}$, con el que su tía Leocadia mantuvo una estrecha relación. Su otra hermana, Joaquina se casó con Charles Robert Beauclerk 6 . Por otro lado, Leocadia era también prima de Jesús Jiménez Zamora, presidente de Costa Rica, de quien la historiografía destaca su frase: «El pueblo que tenga más y mejores escuelas, será el mejor de los pueblos» 7 .

El padre de Leocadia fue un hombre ilustre, «uno de aquellos ejemplos notables de lo mucho que el talento pueda alcanzar cuando está unido con la integridad, con una conducta intachable y con el amor al trabajo» (Molina, 1851: 77). Nacido en Cartago, era hijo de una de las familias más antiguas del país. A los trece años fue enviado a estudiar a la ciudad de León donde permaneció seis años hasta graduarse. Después pasó a Guatemala y allí realizó una pasantía durante dos años. En 1809 emprendió viaje a Madrid llevando recomendaciones para la Audiencia; allí la suerte le deparaba un duro golpe, su buque fue apresado por los corsarios en la travesía de Honduras a La Habana y le robaron todo lo que llevaba consigo. Desembarcó en La Habana sin recursos para continuar el viaje y decidió quedarse y ejercer su profesión. Pronto pudo reponer sus pérdidas y adquirir reputación; gracias a sus

\footnotetext{
4 Rafael Zamora y Pérez de Urría (18?2?-1908), escritor, nació en el concejo de Carreño sin que se sepa el año exacto, en el siglo XIX. El marqués de Valero de Urría se instaló en Oviedo tras fundar su tía Leocadia Zamora un convento de Carmelitas Descalzas en la ciudad. Formó parte de la Extensión Universitaria. Escribió algunos artículos y obras con el sobrenombre de Iscariotes Val de Ur. Fue director de la Escuela de Artes e Industria en 1901, vicepresidente de la Cruz Roja en 1904, y primer presidente de la Sociedad Filarmónica de Oviedo. Falleció en Oviedo en 1906.

5 Nicolás Peñalver Zamora (La Habana, 1853 - Madrid, 1916) fue tres veces Diputado a Cortes por Oviedo (1891-92, 1896-98, 1898-99); fue senador por la provincia de Matanzas (1884-85) y Oviedo (1899-1907), y vitalicio (1907). Fue tres veces alcalde de Madrid (1892, 1895-1896, 1907-1909). Como alcalde contribuyó en la construcción de la Gran Vía y creó la Asociación Matritense de Caridad y otros servicios como la Banda Municipal. El 27 de junio de 1881 sucedió a su padre Narciso José de Peñalver y Peñalver en el título de conde de Peñalver. En 1916 sucedió a su tío lgnacio de Peñalver y Calvo en el título de marqués de Arcos. 6 Charles Robert Beauclerk (1802-1872) era descendiente de la casa ducal de Saint Albans, bastarde de la Real de Stuart (hijo legítimo de Charles George Beauclerk).

7 Jesús Jiménez Zamora (Cartago, 1823 - 1897) era hijo de Ramón Jiménez Robredo y Joaquina Zamora Coronado (hermana del padre de Leocadia). Fue Presidente de Costa Rica de 1863 a 1866; en 1868 derrocó al presidente electo, pero fue muy impopular siendo derrocado en 1870. Entre los logros de su gobierno está la educación: fundó el colegio San Luis Gonzaga. Organizó la educación primaria y la declaró gratuita y obligatoria en 1869. Estableció una Escuela Normal para maestros en San José en 1869 y la Inspección de Escuelas. Contrató profesores europeos para orientar la educación. Manejó las finanzas públicas con austeridad, fundó el Banco Anglo Costarricense, realizó el censo de población, abolió el monopolio del tabaco, fundó el Registro Público de la Propiedad, impulsó la creación de la Casa de Reclusión de Mujeres. Fue padre del tres veces Presidente de la República, Ricardo Jiménez Oreamuno. En: http://www.asamblea.go.cr [1-Xl-2015]
} 198 
aptitudes fue llamado a la Audiencia de Puerto Príncipe y en esa ciudad se casó y estableció su domicilio. En 1826 fue nombrado asesor de la Superintendencia de La Habana, sustituyendo al superintendente en sus ausencias y enfermedades. En 1845 obtuvo la regencia de la Audiencia de La Habana. Tras lo cual, en 1849, fue designado como vocal de la Junta Suprema de tribunales del reino en Madrid. Zamora no solo se distinguió como jurisconsulto y administrador financiero, sino también como escritor. Su Biblioteca de legislación ultramarina (1844-46) fue una obra muy apreciada y consultada. Además, escribió numerosos informes sobre el gobierno de la isla de Cuba que enviaba a España.

Sobre su hija Leocadia, la primera noticia - que tenemos constancia- de su presencia en España data del 17 de septiembre de 1844: el diario El Heraldo (1844: 3) en su "Gacetilla de la capital» se hacía eco de la celebración que, con motivo de los «días de la condesa viuda del Montijo», había tenido lugar en la casa de campo de la condesa, situada entre los dos Carabancheles. En esa fiesta se inauguraba un teatro recién construido en la casa, en cuyo escenario se cantó «el primer acto de la Norma con admirable propiedad [...] Desempeñaba la parte de Norma la señorita Leocadia Zamora; la de Adalgisa, la sobrina de la condesa; la de Clotilde, su hija menor». Los coros y la orquesta dirigida por el Sr. de Iradier contribuyeron al éxito de la pieza, «del cual cupo la más bella parte a las señoritas de Zamora y de Montijo». Afirmaba el cronista que pocas veces, no ya entre aficionados sino en los teatros públicos, se podían oír piezas mejor ejecutadas; por lo cual «las flores, los aplausos y bravos fueron un justo galardón». Terminada la ópera, prosiguió la reunión en los jardines y salones de la quinta, donde se sirvieron frutas, dulces y helados. La fachada del edificio, los jardines y la galería, lucían iluminados con vasos de colores y los sonidos de la música envolvían lo apacible de aquella hermosa noche de verano. Allí estaban el general Narváez, Zarco del Valle, los duques de Medinaceli y Abrantes, duque de Alba, los generales Concha y Serrano, y la duquesa de Alba, junto a los individuos del cuerpo diplomático extranjero.

Todos ellos compartían la admiración por una mujer de gran sensibilidad e inteligencia, Leocadia Zamora, con una voz musical amenizó las veladas de los más exclusivos salones madrileños del XIX, como los mencionados de la condesa del Montijo o las fiestas del marqués de Arcos. Fue amiga de Francisca y Eugenia de Montijo, y de la reina Isabel II, y según las crónicas tuvo a sus pies a muchos de los españoles ilustres de la época, entre otros, el famoso general Ramón Narváez, apodado el Espadón, que como hemos visto compartía las veladas musicales aplaudiendo a la joven intérprete (Fernández, 1979: 485).

Otro singular evento, que contó con la participación de Leocadia, tuvo lugar en la capital madrileña en 1850, según relataba el diario La Época (2-III-1850: 4). Se trataba de un espectáculo, el de Los cuadros vivos, que entusiasmó a la alta sociedad madrileña de 
aquellos años. La representación de los cuadros había estado proscrita para la aristocracia al haberse convertido, en lugares como el Circo de Paul, en una «diversión inconveniente y casi repugnante». El espectáculo se rehabilitaba ahora, transformado en algo ameno y decoroso, en una casa particular de Madrid, la del señor Zamora. Los cuadros, en esta ocasión, habían sido ejecutados por «las lindas hijas del señor Zamora» y otras jóvenes de buena sociedad. Según el diario, los que tuvieron la fortuna de ser espectadores les tributaron grandes alabanzas, pues era «extraordinaria la habilidad y la inteligencia que la señora doña Leocadia Zamora ha demostrado en la dirección de este recreo tan agradable como bonito». Su ingeniosa idea fue hacer que cada cuadro fuese al mismo tiempo parte de una charada. La que esa noche se ejecutó «significaba el nombre de Rosalía»: en la primera, se imitó el cuadro de Corredera, La prudencia y la hermosura, una de cuyas figuras sostiene una rosa, todo ello reproduciendo el «famoso lienzo de Santa Rosalía, el cual está en el Museo de Madrid». Y para terminar se reprodujo La fe, la esperanza y la caridad, del mismo museo y con idéntica perfección y exactitud que los anteriores.

Numerosos autores reseñaron las virtudes de la joven cubana, pero, sin duda, fue Monte-Cristo el cronista que más líneas dedicó a Leocadia. Y su pluma es, en cierto modo, responsable de la biografía que de ella se ha forjado. El periodista iniciaba la narración de la vida de esta dama en el artículo titulado "Dulces memorias. Los salones de la Regencia», publicado en El Imparcial, el 17 de enero de 1907. A modo de entrevista realizada a una anciana marquesa (que ocultaba su identidad), Monte-Cristo va relatando la vida de Leocadia. La entrevistada, que contaba con un siglo de existencia, evocaba los recuerdos de juventud cuando, ya en la Corte, "íntimamente unida con aquella inolvidable amiga que se llamó Leocadia Zamora, que lo era a su vez de Eugenia de Montijo, frecuentamos la sociedad aristocrática». El autor agradecía a los lectores las rectificaciones que pudieran hacer a los datos aportados por la anciana, por si, en un futuro, se decidía a coleccionar estas Memorias.

La marquesa relata que Leocadia había venido a Madrid muy joven y apenas presentada en sociedad llamó la atención por su hermosura; aseguraba que «fue una estrella de primera magnitud en la sociedad madrileña. En torno suyo giraban no pocos satélites», entre ellos, el citado general Narváez que «fue uno de sus admiradores más rendidos». El cronista incita a su interlocutora: «ella tuvo unos amores desgraciados...»; a lo que la anciana responde que en historias de amores suele influir la fantasía. Si bien - puntualiza-, su amiga le confesaba que había «alguien que la interesaba más que toda su numerosa corte de apasionados»; pero, se negaba a «profanar las intimidades de aquella dama exquisita», que «desengañada y triste, profesó a los cincuenta años en un convento de carmelitas descalzas. Que fue abadesa en Oviedo y allí murió, rodeada del cariño y respeto de todos cuantos la trataron». 
El autor insistía: «- $\dot{\jmath} Y$ quién pudo conmover aquella alma tan bien templada?». Y ella sugería: «-No lo sé; acaso aquel apuesto D. Salvador Bermúdez de Castro ${ }^{8}$, prototipo de los caballeros de su época. Tal vez se vieran en los salones de la condesa del Montijo, donde Leocadia cantaba romanzas con una voz deliciosa, cuyo recuerdo aún me conmueve. Era una verdadera artista y a veces se acompañaba del arpa, que pulsaba admirablemente». Monte-Cristo argumenta que ese caballero, marqués de Lerma, estaría mucho tiempo ausente por su carrera diplomática; efectivamente, había sido embajador en Nápoles, y allí, como antes en el Piamonte, tuvo muchos éxitos; amigo de Francisco Il y de la reina María Sofía, cuando la revolución italiana los expulsó del trono les prestó ayuda. Los reyes le habían regalado un palacio en Roma, Villa Farnesina.

Poco a poco la anciana se aleja del tema, pero retoma el hilo con una curiosa reflexión: «las sociedades giran siempre en torno a una idea, y en su época esa idea era el romanticismo». Concluye afirmando que todas sus amigas, que lo eran también de Leocadia, habían hecho grandes bodas: Eugenia de Montijo fue emperatriz de los franceses; su hermana fue duquesa de Alba; Ángela y Carme Peñaflor fueron duquesa de Medinaceli y marquesa de Villaseca (Monte-Cristo, 1907: 3). El mismo Monte-Cristo volvía tomar la pluma para relatar algunos «episodios de la vida de esta dama, que fue ornato principal de los salones madrileños en aquella época romántica y turbulenta en que se hacía la guerra de «guante blanco» y las conspiraciones se fraguaban no pocas veces al arrullo de los valses aristocráticos» (1921: 1). En esta ocasión el periodista vuelve a contar su llegada a Madrid junto a su familia, y como apenas llegada a la corte fue presentada a la sociedad madrileña en los salones de la condesa del Montijo trabando amistad con las hijas de esta.

En esta ocasión, reitera que fueron sus «fervientes adoradores» hombres muy notables, «hasta se dijo que el general Narváez se hallaba preso en las redes de la gentil criolla; mas ella pasaba altiva y desdeñosa, como Juno, recibiendo impasible los homenajes, escuchando sin conmoverse las tiernas endechas del duque de Rivas, o del general poeta Ros de Olano, mientras el galante Martínez de la Rosa, contemplaba sus hechizos a través de sus lentes». Así trascurrieron los años de vida social de Leocadia, mientras los acontecimientos políticos se precipitaban aproximándose la Revolución, las fiestas mundanas eran continuas, «nunca como entonces pudo tener más exactitud la frase «Bailamos sobre un volcán»» afirma

8 Salvador Bermúdez de Castro y Díez (1817-1888) fue un poeta, historiador y diplomático español. El general Narváez, siendo Jefe de Gobierno, lo envió a México como ministro para restaurar la monarquía. En enero de 1845 llegó a La Habana y de ahí pasó a Veracruz. Aunque el plan fracasó, Bermúdez de Castro permaneció en México hasta agosto de 1847. Después, fue embajador en Nápoles (1853-64). Allí conoció a Matilde Ludovica de Baviera, Reina de Borbón y las Dos Sicilias con la que tuvo una hija adulterina que adoptó en 1879. En 1866 renunció al cargo de embajador en París y se afincó en Roma junto a Matilde. Francisco II de las Dos Sicilias le otorgó los ducados de Ripalda (1859) y de Santa Lucía (1860). Publicó sus Ensayos poéticos en 1840. 
Monte-Cristo. Y añade, «nuestra heroína», que asistió a todas esas fiestas, «fluctuaba ya entre la seducción de aquella vida y su vocación amorosa». En los años de la Revolución y del efímero reinado de Amadeo de Saboya figuró ya muy poco en los salones y, cuando se pronunció el manifiesto de Sandhurst, «la deslumbrante belleza de Doña Leocadia Zamora hacía años que se amparaba tras las rejas del convento». Después de la Restauración hizo una breve aparición en Madrid, para después trasladarse a Oviedo, y fundar un convento de la orden de Carmelitas. Y fue en ese convento donde «el difunto conde de Peñalver halló el precioso retrato de la fundadora, pintado por Madrazo» (Monte-Cristo, 1921: 1).

En la entrevista mantenida con la anciana marquesa, Monte-Cristo afirmaba conocer a Leocadia porque «había pasado largas horas en éxtasis ante su retrato» (1907: 3) en casa del conde de Peñalver, su sobrino. Precisamente, en enero de 1903, pudo admirar el lienzo recién restaurado durante las dos noches de baile en el hall del hotel de la calle del Rey Francisco.

\section{2.- La potencia seductora de un retrato}

Si Leocadia Zamora perduró en la memoria de la alta sociedad madrileña fue en buena medida gracias a ese retrato que Federico de Madrazo pintó en 1847 y que, expuesto en el palacio de los condes de Peñalver, tantos aristócratas y gente de la cultura admiraron durante años. Se trata - en opinión de la crítica- de uno de los retratos más logrados del autor. Así lo describía un cronista de $A B C$ muchos años después de ser pintado:

\footnotetext{
¿Por qué ejerce este cuadro tanta fascinación, tanta potencia seductora, sobre quién lo contempla? Uno de nuestros más grandes escritores y filósofos - Ortega y Gasset- dedicó muchos minutos, y hasta horas enteras, a la observación reposada, a la contemplación casi extática, del retrato de Leocadia Zamora. Lo propio ha ocurrido a otros hombres insignes, e incluso a personas del «estado llano» intelectual, a meros visitadores circunstanciales de Exposiciones y Museos. ¿̇En qué radica la razón o el misterio de ello? El arte de Federico de Madrazo merece, sin duda, una reacción admirativa. Pero en el caso del retrato de Leocadia Zamora la admiración asciende a éxtasis místico... Es la persona retratada la determinante de estos movimientos superadmirativos. Madrazo ha sabido retratarla tan excelentemente que al producirse el encuentro con el cuadro, se piensa más bien que se trata de un encuentro romántico con una mujer auténtica, con una mujer de carne y hueso («la mejor musa» del verso rubeniano), con una mujer que aparece misteriosamente - con el misterio de la era romántica - en el escenario de nuestra propia vida... Y ello explica esa sensación única que la vista del cuadro produce. Ante Leocadia Zamora, inmortalizada en este cuadro, se comparece con la misma emoción temblorosa que embarga al hombre joven cuando, en presencia de la mujer elegida, ha de expresar, más o menos tímidamente, toda la poesía de una primera declaración... (González-Deleito, 1959: 92).
} 202 
Madrazo la representó en toda su juventud y espléndida belleza. De pie, con los brazos cruzados delante, la cabeza ligeramente inclinada y ladeada respecto al cuerpo expresando humildad, cual una Inmaculada Concepción vestida de blanco y con manto azul, rodeada de los atributos de las letanías marianas, Leocadia interpela al pintor con su mirada. Su escote de media luna y las rosas que adornan su vestido parecen reforzar la idea, que la asemeja a la imagen virginal que popularizó Joan de Joanes. La única joya que porta, significativamente, es un brazalete con forma de serpiente, símbolo sobre el que se alza la mujer del Apocalipsis. A su lado se abre la puerta a un jardín donde, al final de la escalera, un pavo real descansa sobre una crátera, símbolo cristiano de la vida eterna.

En el citado artículo de 1903, de La moda elegante ilustrada, Monte-Cristo señalaba que las obras de arte eran muy numerosas en el «hotel» de los condes de Peñalver, pues el conde era un "amateur distinguidísimo y muy inteligente en pintura», que pugnaba con los coleccionistas más entendidos en la adquisición de chef-d'œuvre. La valiosa colección se había visto aumentada ese año con el retrato de una dama de la familia, Leocadia Zamora. La historia del cuadro - afirmaba el periodista - era muy interesante, "como lo fue la vida de su original». Según revelaba Monte-Cristo, el conde de Peñalver, al visitar hacía unos años el convento de carmelitas de Oviedo, «descubrió el hermoso cuadro en una habitación poco frecuentada y en lamentable estado de abandono». Era ese el convento al que Leocadia se había retirado y al que legó toda su fortuna. Al parecer, debido a que el pintor la retrató en traje de baile dejando su busto y los brazos al descubierto, las monjas no se atrevían «a fijar la vista en las para ellas pecaminosas desnudeces», por lo que, el conde de Peñalver pidió a las monjas el cuadro "ofreciéndoles en cambio otro retrato de D. ${ }^{a}$ Leocadia vistiendo el hábito de carmelita, y a más de esto una fuerte suma en metálico». Gracias a la mediación del obispo de la diócesis pudo cerrarse el trato y el cuadro vino a Madrid, «y limpio de polvo, barnizado y encerrado en magnífico marco de talla» pudo ser admirado en el hermoso hall de los condes» (1903: 1). Entre los que admiradores póstumos de la joven retratada se hallaba un antiguo diplomático, embajador de España en Berlín, muy conmovido ante la dama que fue su amiga.

El impacto del cuadro entre visitantes y amigos dejó un reguero de artículos en prensa. En 1923, Dy Safford en sus informaciones de sociedad, hacía referencia a un baile celebrado en casa de la entonces condesa viuda de Peñalver. La protagonista del baile era su nieta, la «gentil Cocolín», convertida en «arrogante muchacha, muy guapa y extraordinariamente simpática, cualidad indispensable para completar la belleza». Su madre, la señora de Areces, volvió a aparecer tal como se presentó «en el último baile de trajes celebrado en casa de la duquesa viuda de Valencia, reproduciendo el famoso retrato» de Leocadia Zamora [figura 2] 
(Dy Safford, 1923: 34). También Margarita Nelken quedó fascinada ante una de «las mujeres de Madrazo». Según afirmaba la autora, recogiendo la opinión de la crítica, Madrazo «fue, además de un pintor muy grande, un maravilloso intérprete, en sus mujeres, de la mujer española». A pesar de que en esa época las mujeres vestían trajes sin líneas y, aunque fueran de baile, se peinaban sin coquetería, sin rizos, y mostraban gestos exageradamente comedidos - según Nelken - , en todas las grandes escuelas de pintura, había mujeres que recogían el encanto íntimo y «perenne de la raza», y concluía preguntando: « $\dot{\partial} Y$ no es verdad que también esta doña Leocadia Zamora y Quesada, por ser joven, arrogante y bella, adquiere, merced al contraste de su «estado» con la actitud impuesta, un carácter de incomparable serenidad?» (1921: 9). Por otro lado, González-Deleito en el texto afirma que Madrazo en sus Memorias, refiriéndose a este cuadro, no vacilaba en denominarlo «su gran amor» (1959: 92).

\section{3.- Musa de artistas, literatos y poetisas}

El Archivo del Museo del Prado conserva parte de la correspondencia que Leocadia Zamora mantuvo con Federico de Madrazo con motivo de la realización de su retrato, así como sobre las recomendaciones en torno al retrato de su sobrino John Bullito [sic]. En las cartas se aprecia que modelo y pintor mantenían una relación cordial, pues le pide que perfeccione el retrato porque a pesar de encontrarle cada día más parecido al niño:

...sería una lástima que por falta de algunas pinceladas más quedase imperfecto, y completamente digno del genio distinguido de V. [...] Difícil es, imposible tal vez, que V. pueda coger al vuelo estos pequeños rasgos de semejanza, pero por satisfacer en lo posible a mi hermana y el propio interés que ponemos en ello, me atrevo a arriesgar estas observaciones que en tan cortas y turbulentas sesiones no fue posible cogiese el delicadísimo pincel de $\mathrm{V}$.

Asimismo, el modo en que se despide muestra que la joven cubana compartía aficiones con la familia Madrazo: "Olvidaba suplicar a V. que si le fuese a V. posible proporcionarme la composición en verso que me ha gustado tanto oír recitar de La rosa blanca y el Recluta, de su hermano de V. lo estimaría a V. mucho»`. En otra carta, Leocadia le agradece al pintor el interés que toma en «perfeccionar cuanto sea posible» ${ }^{10}$ su retrato $y$, si juzga nece-

9 ARCHIVO MUSEO DEL PRADO (en adelante AMP). Colección Familia Madrazo. AP. 11 -Exp. 59. "Carta de Leocadia de Zamora [y Quesada] a Federico Madrazo por la que le comenta el retrato de su sobrino John Bullito (sic)», 17-VII-1840.

10 AMP. Colección Familia Madrazo. AP. 11-Exp. 60. "Carta de Leocadia Zamora [y Quesada] a Federico Madrazo por la que le agradece el interés que tiene en perfeccionar su retrato y le habla de su próxima cita», c. 17-VII-1846. La carta lleva fecha del miércoles 25. Otra de las cartas, AP. 11-61, que parece de la misma época, pero anterior a esta, sugiere que si quiere retocar el cuadro ha de ser esa semana, y tiene fecha de marzo 23

Dossiers Feministes, 21, 2016, 195-214 - ISSN: $1139-1219$ - DOI: http://dx.doi.org/10.6035/Dossiers.2016.21.12 
saria una sesión más, acudiría a su estudio al día siguiente. Anterior a ambas, con fecha 4 de febrero, la modelo se dirige al pintor para fijar el precio del cuadro antes de posar para él:

Sr. Dn. Federico Madrazo. / Demasiado conozco que el arte precioso de V. y su reconocido mérito no tienen precio, pero mamá me manda decir a $\mathrm{V}$. que en consideración del retrato de S. M. que de preferencia le ha confiado a V. mi papá para su difícil desempeño y debiendo ser el mío aunque de cuerpo entero mucho más sencillo en el traje y adornos, espera pues de la complacencia de $\mathrm{V}$. le fije para ella en 10.000 reales.

Yo sentiría tanto que el no convenir V. pudiera retrasar la 1. a sesión de mañana. Yo cuidaré pues mañana mismo a eso de las 10 mandar a informarme si me espera $V$. entre 11 y 12 para empezar. /Créame V. su muy adicta / Leocadia Zamora / Febrero $4^{11}$.

Efectivamente, así lo anotó el pintor en su libro de cuentas: «Madrid, 1847. 56.Retr., cuerpo entero, de la Srta. D. ${ }^{a}$ Leocadia Zamora, vestida de blanco con manto azul. $10.000 »^{12}$.

Tal y como las crónicas se ocuparon de reseñar, entre los admiradores más fervientes de Leocadia Zamora estuvo el embajador norteamericano Washington Irving. El anciano diplomático, escritor de los Cuentos de la Alhambra, se sintió fascinado por la joven, que aunque admiraba su talento nunca le correspondió. González-Deleito al evocar la vida de Leocadia asegura que «su belleza, su juventud, su relieve social, su condición de dama singularmente apta para provocar los enamoramientos más apasionados y sinceros», todo llevaba a la «más lírica emotividad, [...a] la necesidad de sumergirse en el ayer romántico». Pero, afirmaba, que no siempre se ha escrito con rigurosa exactitud sobre su vida, se ha fantaseado sobre aspectos como la irreal versión de que Leocadia se sintió atraída por el escritor norteamericano, pues aunque en las fiestas "ella gustaba de su compañía», lo hacía en parte para evadir el asedio de los jóvenes que le pedían «reserva de una polca o una mazurca». Según esas «versiones antihistóricas», la joven se había recluido en el claustro al darse cuenta de que el diplomático no sería su marido por el desequilibrio de edad. El periodista -en una entrevista con la marquesa de Argüeso, "dama auténticamente aristocrática en cuya residencia se conserva y venera el famoso retrato»- desmiente la versión:

Entre Leocadia Zamora y Washington Irving hubo una buena relación amistosa, nacida en bailes y saraos del Madrid isabelino. El embajador norteamericano se sintió atraído, fascinado,

\footnotetext{
11 AMP. Colección Familia Madrazo, AP. 11-Exp. 62. «Carta de Leocadia de Zamora [y Quesada] a Federico Madrazo por la que le pregunta sobre el precio de su retrato», 17-VII-1846.

12 AMP. Archivo personal de la Familia Madrazo. Memorias de mi vida. «Inventario de los cuadros de Federico Madrazo». Sin Catalogar.
} 
por Leocadia. Llegó a enamorarse de Leocadia. [...] Admiraba la labor literaria de este, sentía respeto por el diplomático, por el buen hombre de mundo que era Washington Irving. Pero jamás pensó en ser la mujer de quien, además de llevarle más de treinta años, estaba ya afectado por achaques y dolencias envejecedoras...

[...] es imaginaria la referencia de que Leocadia hiciere un viaje al extranjero y, a su retorno, decidiera el ingreso en el convento. Efectivamente, hizo un viaje; pero no al extranjero, sino a la isla de Cuba, que entonces era territorio español. [...] Fue allí cuando empezó a sentirse despegada del mundo...

[...] Hubo por entonces quien se interesó por Leocadia: el marqués de Arcos, joven aristócrata, muy enamorado de ella. Pero Leocadia se sintió atacada por una neurastenia creciente... La familia observó, alarmada, que ya no quería bailes, ni saraos, ni recepciones... Nada... Al volver a la Península, Leocadia decide ingresar en la Orden de las Carmelitas. Profesa, efectivamente. Son cortados sus hermosos cabellos. Y es cubierto su cuerpo (rosa, nácar, seda...) con las ásperas vestiduras monjiles... Leocadia funda el convento [...] donde muere [...] Allí la visitó su sobrino don Nicolás de Peñalver y Zamora, conde de Peñalver, gran alcalde de Madrid... [...] La mujer que inspiró tan grande amor a Washington Irving lque siempre la llamaba «mi favorita» en las cartas a sus amigos) era ya vieja y desdentada (González-Deleito, 1959: 92).

Además, de este artículo, $A B C$ ha dedicado otros muchos a la relación entre la joven cubana y el diplomático americano. En 1950, la crónica afirma que «si la palabra flirt pudiera hallar uso apropiado a las costumbres del pasado siglo, no hay duda que habría que aplicarse al sentimiento que ligó a estos dos personajes», Leocadia Zamora y Washington Irving. Fue en los saraos que la condesa de Montijo organizaba en su palacio de la plaza del Ángel, donde Irving conoce «a la beldad de moda», pero la joven evadía los galanteos (Oliván, 1950: 11). En 1957, de nuevo un artículo dedicado a «El primer turista americano» retoma el tema. El autor, conde de Foxa, narra el devenir del diplomático, los meses que vivió en la Alhambra cuando era un lugar abandonado donde «los gitanos encendían hogueras ahumando los techos de oro del Salón de los Embajadores», su vuelta a Nueva York, y el regreso a España en 1842 como embajador donde «le sorprendió el amor» (1957: 10).

Según De Foxa, hacía dos años, «el director del Museo Romántico de Madrid y gran escritor, Mariano Rodríguez de Rivas, [le] entregó el álbum (mutilado, con muchas hojas cortadas en un implacable otoño) de Leocadia Zamora». El periodista afirma que «el amor en aquella época era obligatoriamente desgraciado», y asegura que la joven cubana fue «el gran amor - el único amor - de Washington Irving. He contemplado sus cartas enternecidas, y en su álbum aún se escuchan suspiros. Allí está escrito a Leocadia Zamora un romance de Gertrudis Gómez de Avellaneda, que creo inédito, en el que le habla de la patria lejana, de sus ciclones, de la flor del café, de la caña y el tabaco» (1957: 10). Más recientemente, en

206

Dossiers Feministes, 21, 2016, 195-214 - ISSN: $1139-1219$ - DOI: http://dx.doi.org/10.6035/Dossiers.2016.21.12 
1999, de nuevo el diario $A B C$ retomaba el asunto sobre «El amor desconocido de Washington Irving» que concluía con la pregunta: «¿Qué se ha hecho de aquel álbum de la cubana Leocadia Zamora? ¿ ¿e conocerán las cartas amorosas que el escritor diplomático le dirigió a la bella criolla? Quizá algún día podamos leer esas páginas que Washington Irving durante sus días en Madrid, escribiera a esa cubana peregrina» (Bueno, 1999: 40).

Desconocemos el paradero del álbum, sin embargo, sí hemos localizado el poema que le dedicó la escritora Gertrudis Gómez de Avellaneda, también de origen cubano, titulado El último acento de mi arpa, "A mi querida amiga la señorita Leocadia de Zamora», que forma parte del libro Poesías (1850). En el Prólogo escrito por el Excmo. Señor D. J. N. Gallego en el tomo primero de estas poesías, cuando se hizo su primera impresión (Madrid, noviembre de 1841), el prologuista señalaba que, aunque para componer versos sea menester reposo y tranquilidad de espíritu, los españoles tenemos el asombroso privilegio de desmentir aquel axioma y a pesar del estruendo y horrores de la guerra civil y los disturbios políticos crecía el número de autores y poetas, «incluso al menos seis damas españolas cultivaban la lengua de los dioses». Presentar la publicación de un tomo de poesías, escritas por una mujer, era algo poco frecuente en cualquier país, y rarísimo en el nuestro. Era un libro fruto del gran talento y ardiente afición de la señorita doña Gertrudis Gómez de Avellaneda. Los editores señalaban, en la Noticia Biográfica que acompañaba a la edición de ese segundo tomo de poesía lírica, que «nuestra poetisa» creía que será el último, pues le parecía «que con los postreros acentos que ha consagrado a su hermosa y tierna amiga la señorita Doña Leocadia de Zamora se despide para siempre de la poesía lírica; sin duda piensa que cuando la amistad le ha inspirado tan deliciosas melodías, nada le queda por cantar». Sin embargo, los editores creían que a pesar de ser muy digno «coronar la vida del alma con un afecto inspirado por la interesante Leocadia», la Señora de Avellanada todavía guardaba tesoros, y afirmaban que Tula se despedía «colgando su arpa para sentarse en su pedestal». La propia autora confesaba en el Prefacio: «rompo para siempre las cuerdas de la lira, que no vibra agradablemente sino en manos de la juventud, al soplo poderoso de las pasiones ardientes. Con treinta y cuatro años, y un corazón cansado por la desventura, me siento incapaz de proseguir la carrera de poeta lírico» (1850: II).

\section{4.- El retiro al monasterio}

En el catálogo de la exposición, El mundo de los Madrazo, se afirma que fue en 1852 cuando Leocadia regresó a Cuba por la muerte de su padre y siete años después se instaló en Barcelona. Tras la revolución de 1868 se exilia a Londres y luego se traslada a 
Roma. En 1871 regresa a Barcelona y al año siguiente se recluye en un convento en Alba de Tormes. Convertida ya en Madre Ana Teresa de la Sagrada Familia marchó a Oviedo para fundar un monasterio. En 1884 inauguraba en el barrio de San Lázaro el primer convento de carmelitas descalzas que hubo en Asturias. Allí falleció en 1891, y según los autores «actualmente está en proceso de beatificación» (González; Martí, 2007: 242). Leocadia conservó hasta su muerte el retrato pintado por Madrazo, que después pasó a los condes de Peñalver como hemos visto. Vivió cautivando con su voz y sus encantos a los más insignes de la política y la cultura en los salones castizos de la España isabelina que cambió por la vida monacal.

En El libro de Oviedo: guía de la ciudad y su concejo, Fermín Canella y Secades afirma que las obras del convento de carmelitas fundado por Leocadia Zamora empezaron en 1882 bajo la dirección de «Federico Aparici, arquitecto de Madrid, siendo patrono y principal bienhechor el Sr. D. Rafael de Zamora y Quesada, marqués de Valero de Urría» (1887: 242). Fue de su hijo, Rafael de Zamora y Pérez de Urría, de quien supuestamente se enamoró su tía.

A este III marqués de Valero de Urría dedicó Marco Antonio Iglesias dos artículos. En el texto de 2006, «Los crímenes del marqués. Dandismo, parnaso y bohemia en el Oviedo de fin de siglo», comentaba cómo su extraña figura fascinó en su día a quienes tuvieron el placer de conocerle, y sigue fascinando a los amantes de las rarezas literarias. El excéntrico marqués fue un «renombrado bohemio en el Oviedo «regentado» por Clarín y quizás el parnasiano español más consciente de serlo». Rafael de Zamora y Pérez de Urría veía la luz en París, el 21 de noviembre de 1861. Allí fue bautizado siendo padrinos sus tíos los condes de Peñalver. Era hijo de Rafael de Zamora y Quesada y de María de la Concepción Pérez de Urría y de la Cuesta, casados en La Habana en 1860. Cuando murió su madre en 1886 heredó el título. Estudió en La Sorbona y luego en Salamanca. Al parecer motivaron su trasladó a Asturias «tanto las propiedades de su mujer en el Principado - de donde era oriunda su familia - como la sorprendente decisión de su tía paterna, doña Leocadia Zamora y Quesada, de hacerse monja y formar en Oviedo la orden de las Carmelitas descalzas» (Iglesias, 2006).

Según Antón Rubín, «Valero de Urría, alto y corpulento, con marcado aire cosmopolita y trayendo al recato de la silente Vetusta el escándalo europeo del dandismo» (Iglesias, 2006). Pero no todo fue escándalo, pronto el marqués se hizo un hueco en los cafés, los salones y los ambientes más selectos de Oviedo. Helenista consumado y latinista perfecto, en palabras de Azorín, una vez instalado comenzó a tratarse con lo más granado de la sociedad ovetense. Fue uno de los fundadores y el primer presidente de la Sociedad Filarmónica de Oviedo, incluso compuso algunas piezas para canto y piano. Dirigió la Escuela de Artes y Oficios de Oviedo (1901) y la Cruz Roja. Impartió cursos en la Extensión Universitaria, el más 
sonado versaba sobre un desconocido «Baudelaire y la métrica francesa» (1901-1902), donde tuvo como alumno a su discípulo y amigo Ramón Pérez de Ayala. La afición al coñac y al aguardiente del marqués no le impidió participar en las tertulias, $y$ «como todo buen «dandy» que se precie, construyó su peculiar torre de marfil donde rendir culto a la belleza eterna», ubicada en la calle de Uría, donde reunió una impresionante colección de libros raros. El único libro que dejó escrito es una auténtica joya bibliográfica con el delirante título de Crímenes literarios y meras tentativas escriturales y delictuosas perpetrados por el profesor don Iscariotes Val de Ur, catedrático de Paleografía, Criptología y Zoophonía en la Universidad de Polanes (1906). Bajo el pseudónimo se oculta el propio Valero de Urría, cuya biografía es ofrecida al lector por su discípulo Rafael Urdeval, de nuevo un anagrama. El libro es ejemplo del surrealismo temprano cultivado en España (Iglesias, 2008).

Sobre la relación amorosa de Leocadia Zamora con su sobrino no tenemos más datos que lo apuntado, pero en la Sección Nobleza del Archivo Histórico Nacional, en el fondo documental del Archivo de los Condes de Peñalver, se conservan numerosos documentos relativos a la familia Zamora, la mayor parte en relación a la herencia de María de los Ángeles Quesada y los derechos y donaciones otorgados a los hermanos y sobrinos de Leocadia, como un codicilo cerrado entregado ante notario. Entre esos registros se encuentran las "Cartas de Ana Teresa Zamora, carmelita descalza, a su sobrino Nicolás de Peñalver, referentes a la fundación de un nuevo convento en Asturias, y a asuntos familiares» que, aunque no hemos podido consultar todavía, sin duda, aportarán datos interesantes en torno a la fundación del convento y a las relaciones que Leocadia mantuvo con sus dos sobrinos, el marqués de Valero de Urría y el conde de Peñalver.

Por último, mencionaremos una publicación que podría estar vinculada a Leocadia Zamora. En 1868, Amalia de Llano y Dotres, condesa de Vilches, otra de las más bellas mujeres de la corte isabelina también retratada por Federico de Madrazo, publicó una novela con el título Ledia, bajo el pseudónimo de condesa de ***. La autora aclara en la primera nota «Ledia, es diminutivo de Leocadia». La condesa de Vilches compartió con Leocadia Zamora los círculos de sociabilidad madrileños de mediados de siglo, ambas fueron amigas de la reina Isabel II y de las hijas de la condesa de Montijo, y las dos cantaron en los salones de la época. La novela cuenta la historia de una joven viuda, prometida a su sobrino, que se enamora de un poeta. Ledia tiene como confidente a un anciano donjuán que la corteja y aconseja. No puede renunciar al matrimonio con su sobrino porque hay un codicilo sobre la herencia de su marido que le obliga a casarse con él. Ledia acaba renunciando a la herencia y recluyéndose en un monasterio. Finalmente, el apasionado poeta destinado como diplomático a Berlín descubre dónde se oculta Ledia y acude al monasterio, le declara su amor y se marchan juntos. 
Para concluir, reproducimos la curiosa sentencia de uno de tantos cronistas que se ocuparon en $A B C$ de la relación entre «Washington Irving y la España romántica. Y recuerdo de sus románticos amores con Leocadia Zamora», quien tras enumerar una vez más el mismo supuesto enamoramiento concluía con una profecía sobre la vida de esta mujer singular:

La obra y el recuerdo del gran poeta en prosa que nos mandó Norteamérica serán imperecederos en España. Su historia agitada nos parece como un capítulo más de sus propias narraciones. En cuanto a Leocadia, la bella cubana que vino a enterrar sus ilusiones al borde nuestro nórdico mar, solo queda de ella un leve recuerdo, como un rayito de luz entre la niebla (J. E. Casariego 1959: 39).

\section{Bibliografía}

Barrado Barquilla, José (1996): Fray Ramón Martínez Vigil, O.P. (1840-1904) Obispo de Oviedo, Salamanca, San Esteban, p. 362.

Bolufer, Mónica (2014): «Multitudes del yo: biografía e historia de las mujeres», Ayer 93, pp. 85-1 16. BUENO, Salvador (1999): «El amor desconocido de Washington Irving», ABC, 8-X-1999, p. 40.

CAMON AzNAR, José (1956): «Los dos romanticismos», $A B C, 12-X I 1-1956$, pp. 15 y 19.

CANella Y SECADES, Fermín (1887): El libro de Oviedo: guía de la ciudad y su concejo, (Ed. facsimilar, Maxtor, 2015), Oviedo, Imp. de Vicente Brid, p. 242.

CASARIEGO, J. E. (1959): «Washington Irving y la España romántica. Y recuerdo de sus románticos amores con Leocadia Zamora», ABC, 9-XII-1959, pp. 37 y 39.

DE FoXA, Agustín (1957): «El primer turista americano», ABC, 24-III-1957, pp. 10-11.

Díez HuerGa, M. Aurelia (2006): «Salones, bailes y cafés: costumbres socio-musicales en el Madrid de la reina castiza (1833-1868)», Anuario musical, 61, pp. 189-210.

El Heraldo (Madrid), «Gacetilla de la capital», 17-IX-1844, p. 3.

EzQuerRa Del Bayo, Joaquín y Luis Pérez Bueno (1924): Retratos de mujeres españolas del siglo XIX, Madrid, Imprenta Julio Cosano, p. 181.

Fernández PIZA, Mario (1979): «Don José María de Zamora y Coronado», Revista Hidalguía, 154155, pp. 481-485.

GallNOSA, Luis de (1928): «Los Pintores de la Mujer», Blanco y Negro, 6-V-1928, pp. 74-77.

GallEGO, Julián (1994): «Lo mejor del mejor de los Madrazo», Cultural ABC de las artes, 25-XI1994, pp. 27-28.

González López, Carlos; Martí Ayxelá, Montserrat, dir. (2007): El mundo de los Madrazo (Exposición Colección de la Comunidad de Madrid), Madrid, Comunidad de Madrid, Consejería de Cultura y Deportes.

210

Dossiers Feministes, 21, 2016, 195-214 - ISSN: $1139-1219$ - DOI: http://dx.doi.org/10.6035/Dossiers.2016.21.12 
GonZÁlez-Deleito, Nicolás (1959): «Mujeres españolas: Leocadia Zamora (El triunfo del amor divino)», Blanco y Negro (Madrid), 25-7-1959, p. 92-93.

Gómez De Avellaneda, Gertrudis (1850): Poesías, Madrid, Imprenta de Delgrás Hermanos. Pretil de los Consejos.

IGLESIAS, Marco Antonio (2006): «Los crímenes del marqués. Dandismo, parnaso y bohemia en el Oviedo de fin de siglo», Clarín Revista de Nueva Literatura, 17--1-2006.

En: www.revistaclarin.com [27-X-2015].

(2008): «El «dandy» más adorable de Oviedo. Primer centenario del fallecimiento de Rafael de Zamora», Diario Independiente de Asturias, 20-V-2008. En: www.Ine.es [27-X-2015].

La Época (Madrid), 2-III-1850, n³05, p. 4.

Molina Bedoya, Felipe (1851): Bosquejo de la república de Costa Rica: seguido de, apuntamientos para su historia con varios mapas, vistas y retratos, (San José, Costa Rica, Editorial Universidad Estatal a Distancia, 2007) New York, Imp. de S.W. Benedit, pp. 77-82.

MONTE-CRISTO (1903): «De casa y de fuera», La moda elegante (Cádiz), 30--1903, p. 4.

(1907): «Dulces memorias. Los salones de la Regencia», El Imparcial (Madrid), 17--1907, p. 3.

(1921): «Crónicas retrospectivas», El Imparcial (Madrid), 17-IV-1921, p. 1.

(1925): «El Hotel de la Condesa de Peñalver», Blanco y Negro (Madrid), 7-VI-1925, pp. 100-103.

NelKen, Margarita (1921): «Las mujeres de Madrazo», El Imparcial, 10-IV-1921, p. 9.

Ouván, Federico (1950): «Leocadia Zamora y Washington Irving», ABC, 6-VII-1950, p. 11.

SAFFORD, Dy (1923): «Informaciones de sociedad. En casa de la condesa viuda de Peñalver», Blanco y Negro (Madrid), 4-II-1923, pp. 34-36.

EL ÚLTIMO ACENTO DE MI ARPA.

A mi querida amiga LA SEÑORITA DOÑA LEOCADIA DE ZAMORA.

Lo siento joh amiga! Mi mente

Ya plega sus alas,

Marchitas sus galas,

Pasado su abril.

El tiempo en su rápido giro

Se lleva veloces

Mis plácidos goces

De edad juvenil.

No hay ya para mi poesía 


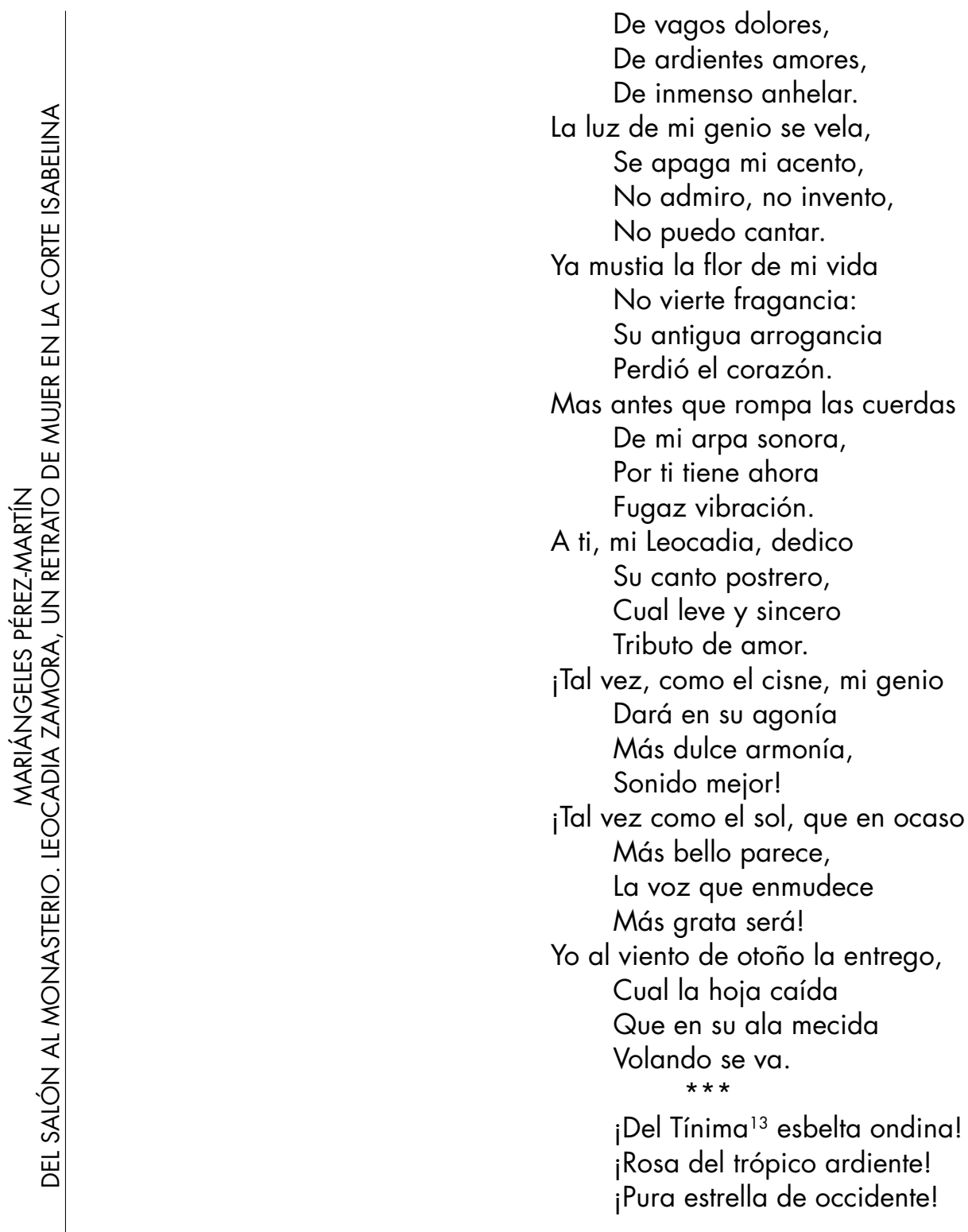

212

13 El Tínima es uno de los ríos que atraviesan la ciudad de Camagüey (hasta 1898 Puerto Príncipe), situada en la zona centro-oeste de la isla de Cuba. Gertrudis Gómez de Avellaneda nació en Puerto Príncipe en 1814.

Dossiers Feministes, 21, 2016, 195-214 - ISSN: $1139-1219$ - DOI: http://dx.doi.org/10.6035/Dossiers.2016.21.12 
¡Sirena hermosa del mar! ¡Yo quiero mostrarte mi afecto ferviente! ¡Yo quiero en mis versos tu gloria fijar!

Cuando parte de tus ojos

Un rayo de amor divino,

Que el sol se corre imagino

De no poderlo imitar:

¡Así será siempre tu fausto destino, A cuanto más brille vencer y eclipsar!

Cuando exhalas de tus labios

Los dulcísonos acentos,

Fuentes, aves, mares, vientos,

Se suspenden a la par;

Que no hay en natura tan varios concentos

Como estos que sabes tú sola formar.

La noche envidia la sombra

De tu profusa melena;

Mas que la luna serena

Se ve, bajo ella brillar,

Con mágico encanto tu frente morena,

Que regia corona merece llevar.

Donde se graban tus huellas

Brotan rosas y alelíes;

En el lugar donde ríes

Va la aurora a despertar,

Y aljófares muestras, partiendo rubíes,

Que nunca sus perlas podrán igualar.

¿Quién te escede en donosura?

¿Quién te copia en gallardía...?

¡En la Grecia se alzaría

Para tu culto un altar,

Y en ti más sublime deidad gozaría

Que aquella nacida del seno del mar!

Mas hoy que humilla al Olimpo

Divinidad soberana,

De los ángeles hermana

Te puede el cielo llamar,

Y el mundo te aclama beldad sobrehumana, 
Que huella la tierra queriéndola honrar.

El genio anima tu mente;

La virtud rige tu alma;

Por eso pasión y calma

Unidas sueles mostrar;

Y llevas do quiera del triunfo la palma,

$Y$ puedes modesta tu gloria olvidar.

¡Rosa del trópico ardiente!

¡Del Tínima esbelta ondina!

¡Quisiera tu voz divina

Para poderte ensalzar;

Pues siento la mía turbada y mezquina,

Y solo en silencio te debo admirar!

Mas si algún eco del arpa,

Que hoy a romper me decido,

Logra vencer al olvido

$Y$ al voraz tiempo burlar,

A par de mi nombre tu nombre querido

Por siglos futuros se oirá resonar.

¡Que yo en mi canto proclamo

Que, bajo de humano velo,

Un ángel mora en el suelo

Para mis penas templar,

Y haré que la fama lo estienda en su vuelo,

Por cuanto el sol mira y abarca la mar!

Noviembre de 1850 (Gómez de Avellaneda, 1850: 309-311).

Recibido el 15 de enero de 2016

Aceptado el 1 de marzo de 2016

BIBLID [1 139-1219 (2016) 21: 195-214

Dossiers Feministes, 21, 2016, 195-214 - ISSN: $1139-1219$ - DOI: http://dx.doi.org/10.6035/Dossiers.2016.21.12 